\title{
21
}

\section{Geographic Information and School Facility Planning}

\author{
Raymond G. Taylor \\ North Carolina State University, Box 7801, Raleigh, NC, 27695, USA
}

\begin{abstract}
Recent advances in microprocessor technology have made it possible to find mathematically optimal solutions for school facility planning. Beginning with accurate forecasts based on historical data (such as those available through gradient search, cohort survival methodologies), and supplemented by future-oriented methodologies (such as traditional land use studies), it is possible to gauge expected future growth in a school system and to allocate that growth to specific regions. By disaggregating growth to the building attendance-area level and comparing that disaggregation to building capacities, the out-ofcapacity (OOC) status for each building for each future year can be determined. By color coding the OOC status for each building for any one year, a computer generated map can be used to examine geographic relationships of OOC problems.

Here the most significant recent advance in technology comes to bear upon the problem -finding the optimal location for capital projects (new construction, expansion, replacement, or closing). Using a nonlinear discrete optimizer (such as GAMS 2.25, driving MINOS $5{ }^{*}$ ) the geographic coordinates of new schools can be identified, and the selection of existing schools for capital projects can be specified, such that transportation is minimized and all other mathematically specified school board policies are honored (racial balance, overcrowding, etc.). Finally, simple binary programming can be used to fix the attendance boundaries for all new and existing schools, assuming that student locations or addresses have previously been geocoded.
\end{abstract}

Keyword Codes: $\quad$ G.2.m; I.3.8; J.1

Keywords: Discrete Mathematics Miscellaneous; Computer Graphics Applications; Computer Applications Administrative

\section{INTRODUCTION}

New schools are normally built as existing schools become crowded or obsolete. Thus, the optimal location for a new school must take into account the location and capacity of existing schools, the location of students, and which students will attend which schools after the new school is built. Mathematically, this is a considerably more complex question than simply deciding where to build a new school for the purpose of serving a predetermined population.

* General Algebraic Modeling System (Software), GAMS Development Corp., Washington, DC 
If the population of students who will attend a new school is already known, then the $\mathrm{X}$ and $\mathrm{Y}$ coordinates for the most central location for the new school is simply the average of the $\mathrm{X}$ coordinates of the students and the $\mathrm{Y}$ coordinates of the students. However, when the new school (or several new schools) is going to supplement an existing set of schools and the attendance boundaries for all the affected schools will be redrawn, then a more general model is useful.

\section{LITERATURE}

A review of the literature reveals that only a small amount of direction or assistance to school administrators is available on site selection. In general, the literature divides itself into two categories. One category provides processes for developing lists of considerations which should affect site selection. For example, see references (1) and (2). In this approach, a team process is advocated in which planners, architects, engineers, real estate and educational personnel take active roles in evaluating a site. By using information which is already in the public domain, such as topographical maps and soil analyses, an assessment of a potential site can be made in terms of the criteria adopted by the team. Such site criteria might include: the fit of the educational program to the site, convenience, physical shape and characteristics, aesthetics, safety, air quality, soils, availability of water and sewer, environmental hazards, relation of the site to highways, zoning, utility service and police, fire and medical coverage.

The team approach is not contradicted by the method which is described later in this paper. Rather, the two could be profitably used together. Once a mathematically optimal location is known, then the team and list approach could be used to adjust the solution for other technical, social and political criteria.

A second category of literature pertains to quantitative methods for suggesting new school locations. For example, McGuffey (3) provides a model for finding a useful starting point in site selection. Although this model does not claim mathematical optimization, it does illustrate one way of integrating enrollment data from existing school populations with distances to potential new school sites.

A more complex microcomputer model has been described by Tanner \& Holmes (4). Their model is a derivation of the breaking point model, which uses forecast pupil populations and distances to plot site solutions. A refinement of the Oak Ridge National Laboratories method, referred to as the Modified Land Use Screening Procedure for Sating, allows planners to determine a list of acceptable location criteria and student enrollment forecasts to be weighted and used to solve for site locations.

It was not until the later 1980s, however, that microcomputers were powerful enough to provide truly optimal solutions for site locations. In this context, "optimal" means that some criterion is maximized of minimized (such as transportation distance) while any number of constraints are simultaneously met. Those constraints can involve, for example, policies on school size, racial balance, overcrowding, and underutilization.

\section{MATHEMATICAL MODEL}

It is assumed that the school system using this model will have a file of digitized locations for all students, perhaps as a result of using some sort of transportation and/or student management system. Further, it is assumed that the system has divided the total geographic area it serves into smaller planning regions. The distance from the population center of each 
region (R) to the existing school (E) may be measured over-the-road, or may be estimated using either a Euclidean ("as the bird flies") or rectilinear (all measurements are horizontal or vertical) calculation. The over-the-road calculation is tedious and error prone unless the system owns some sort of mapping program which supports stand-alone distance calculations, while the Euclidean distance systematically understates the actual distance. The rectilinear calculation for the distance from each epicenter to the existing school $\left(D_{R}\right)$ is preferred if over-the-road calculations are not readily available. The rectilinear distance is given by:

$D_{R}=\left|X_{R}-X_{E}\right|+\left|Y_{R}-Y_{E}\right|$

where $X_{E}$ and $Y_{E}$ are the coordinates of the existing school, and $X_{R}$ and $Y_{R}$ are the coordinates of the population center of each region.

A similar formula applies to the calculation of distances from each region to the new $\operatorname{school}\left(Q_{R}\right)$.

$Q_{R}=\left|X_{R}-X_{N}\right|+\left|Y_{R}-Y_{N}\right|$

Two decision variables are introduced: $\mathrm{O}_{R}$ and $\mathrm{N}_{R}$. The values of $\mathrm{O}_{R}$ indicate the proportion of students from each $\mathrm{R}$ who should attend the existing school. Generally, students will be assigned to schools by region and the values of $\mathrm{O}_{R}$ will be either 0 or 1 . The same meanings apply to $N_{R}$, the decision variable for the new school. Of course, for every $\mathrm{R}, \mathrm{O}_{\mathrm{R}}+\mathrm{N}_{\mathrm{R}}$ must equal 1 , since all the students in each region must be assigned to one school or the other. Further, $\mathrm{O}_{\mathrm{R}}+\mathrm{N}_{\mathrm{R}}$ must be declared as positive variables, since negative values would be nonsensical.

The objective function $(Z)$ is to minimize the total distance traveled by students. That function is given by

$\mathrm{MIN} \quad Z=\sum_{R} O_{R} D_{R} S_{R}+\sum_{R} N_{R} Q_{R} S_{R}$

where $S_{R}$ is the number of students in region $R$.

The first set of constraints assigns students to one and only one school:

For every R: $O_{R}+N_{R}=1$

The next two constraints make certain that the existing school is not overcrowded or underutilized. Overcrowding is defined as having more students assigned to the school than its design capacity (C), and underutilization is defined as having fewer students assigned to the school than $75 \%$ of its design capacity.

$\sum_{R} S_{R} O_{R} \leq C \quad \sum_{R} S_{R} O_{R} \geq .75 C$ 
The above two constraints could be removed from the model for the purpose of testing the optimal size of the existing school. This might be done, for example, if an addition were being contemplated as well as a new school. Additional constraints could be included to require racial balance, or to meet any other social or technical goal. Further, adding new variables for existing and new schools, any number of either could be accommodated by the model.

\section{FORMULATION}

The model described above is discontinuous, due to the absolute value operations in the distance equations, and is nonlinear, since there are endogenous variables in the objective function. Thus, a fairly "high powered" modeling and optimization package is needed to model the problem elegantly and to solve it efficiently. The use of GAMS, A General Algebraic Modeling System (5), is demonstrated here, but other packages could have been just as easily used. In the example which follows, twenty regions, one existing school, and one new school, are assumed.

A single set, $R$, is declared and defined. It has a range from 1 to the total number of regions. In the illustration which follows, $R=1,2,3, \ldots 20$.

Three scalars are declared and defined. The first is $\mathrm{C}$, the capacity of the existing school. The second and third are $X_{E}$ and $Y_{E}$, the $X$ and $Y$ coordinates of the existing school.

Three parameters, each with $R$ values, are declared and defined. The first is the number of students in each region, $S_{R}$. The second and third are the $X$ and $Y$ coordinates of the population centers of each region, $\mathrm{X}_{\mathrm{R}}$ and $\mathrm{Y}_{\mathrm{R}}$.

Four indexed variables are declared, each over the range of $R . O_{R}$ and $N_{R}$ are the decision variables that indicate the proportion of students in region $R$ who will attend either the existing school, $\mathrm{O}$, or the new school, $\mathrm{N}$. $\mathrm{O}$ and $\mathrm{N}$ are also defined as positive. The other two indexed variables are $D_{R}$ and $Q_{R}$, the distance from the population center of each region to the old and new schools, respectively.

Three non indexed variables are declared. $X_{N}$ and $Y_{N}$ are the unknown $X$ and $Y$ coordinates of the new school. $Z$ is the value of the objective function which is to be minimized. $Z$ equals the total distance from the population center of each region to whichever school(s) is assigned to each region.

Six equations are declared and defined.

1) The first equation computes the distance from the population center of each region to the existing school. See equation [1] above.

2) The second equation determines the manner in which the distance from the population center of each region to the new school must be computed. Because the location of the new school is determined by the optimal solution, and because the optimal solution is dependent upon the distance calculation which is, in turn, dependent upon the location of the new school, the entire model is nonlinear. See equation [2] above.

3) The objective of the model is given as in equation [3] above.

4) The remaining equations are constraints. One of these equations is indexed over the range of $\mathrm{R}$ and makes certain that each region is fully assigned to one school or the other, or to both schools. See equation [4] above.

$5,6)$ The remaining equations prevent overcrowding and underutilization. See equations [5] above. 
The GAMS model concludes with the naming of the model and the command to solve the model, minimizing Z, using Discrete Nonlinear Programming. The nonlinear optimizer used here was MINOS 5. The model can be expanded to include as many existing schools and as many new schools as needed. The author has located two new schools simultaneously within a cluster of fifteen existing schools with over 150 population regions under consideration by simply adding corresponding variables to the above model and expanding each equation to refer to all necessary variables.

Table 1

$\mathrm{X}$ and $\mathrm{Y}$ Coordinates for the Population Center of each Region

$\mathrm{X}$ and $\mathrm{Y}$ Coordinates of the Existing School

\begin{tabular}{lll} 
Region & $\mathrm{X}$ & $\mathrm{Y}$ \\
\cline { 2 - 3 } 1 & 0.59 & 6.82 \\
2 & 3.00 & 7.01 \\
3 & 5.18 & 5.58 \\
4 & 8.21 & 6.82 \\
5 & 0.81 & 4.62 \\
6 & 2.19 & 5.42 \\
7 & 4.40 & 5.20 \\
8 & 5.61 & 4.81 \\
9 & 8.41 & 5.22 \\
10 & 9.81 & 5.00 \\
11 & 0.78 & 2.20 \\
12 & 3.39 & 2.61 \\
13 & 5.18 & 4.01 \\
14 & 6.00 & 3.82 \\
15 & 7.59 & 1.81 \\
16 & 8.21 & 1.81 \\
17 & 1.79 & 0.82 \\
18 & 5.16 & 0.82 \\
19 & 7.99 & 0.41 \\
20 & 9.58 & 1.40 \\
& & \\
School & 3.39 & 4.62 \\
\hline
\end{tabular}

5. EXAMPLE (20 regions, 1 existing school, 1 new school)

Chart 1 is a map of the twenty regions, scaled in miles. The regions are numbered F1 F.2, E3, ... E20. The population centers are shown by small circles. The number of students of the age pertinent to the new school) in each region is also shown. The location of the existing school in region E7 is marked. The twenty regions include 1899 students. The existing school has a design capacity of 1025 , but its current enrollment is nearly 1200 . A second school, presently housing 700 students, is scheduled to be torn down and will be replaced by the new school. The question is, "Where should the new school be built and how many students should be assigned to it, such that the total transportation distance required of all students is minimized and neither building is overcrowded or underutilized?" 
The $\mathrm{X}$ and $\mathrm{Y}$ coordinates of each region and the existing school are given in Table 1 .

\section{SOLUTION}

The solution includes the assignment of each region to one or both schools, the distance to be traveled by students in each region, and the total distance traveled by all students. Most importantly, the solution indicates the coordinates of the new school: $X=6.000, Y=4.010$. The objective function was evaluated at 5,474 , which represents the total of all student/miles traveled per half-day (i.e., in one set of trips). Most of the solution is presented in Table 2.

Of course, in practice, it would be unusual to be able to build the school exactly where indicated. Thus, Chart 2 shows the optimal location in the middle of a set of concentric rings. Theoretically, the areas in the inner rings represent a better set of solutions than those in the outer rings, but the availability of land, major highways, suitable sites, and so on will dictate what is truly optimal.

Table 2

Assignment of Regions to Schools and Corresponding Distances

Optimal Location of New School

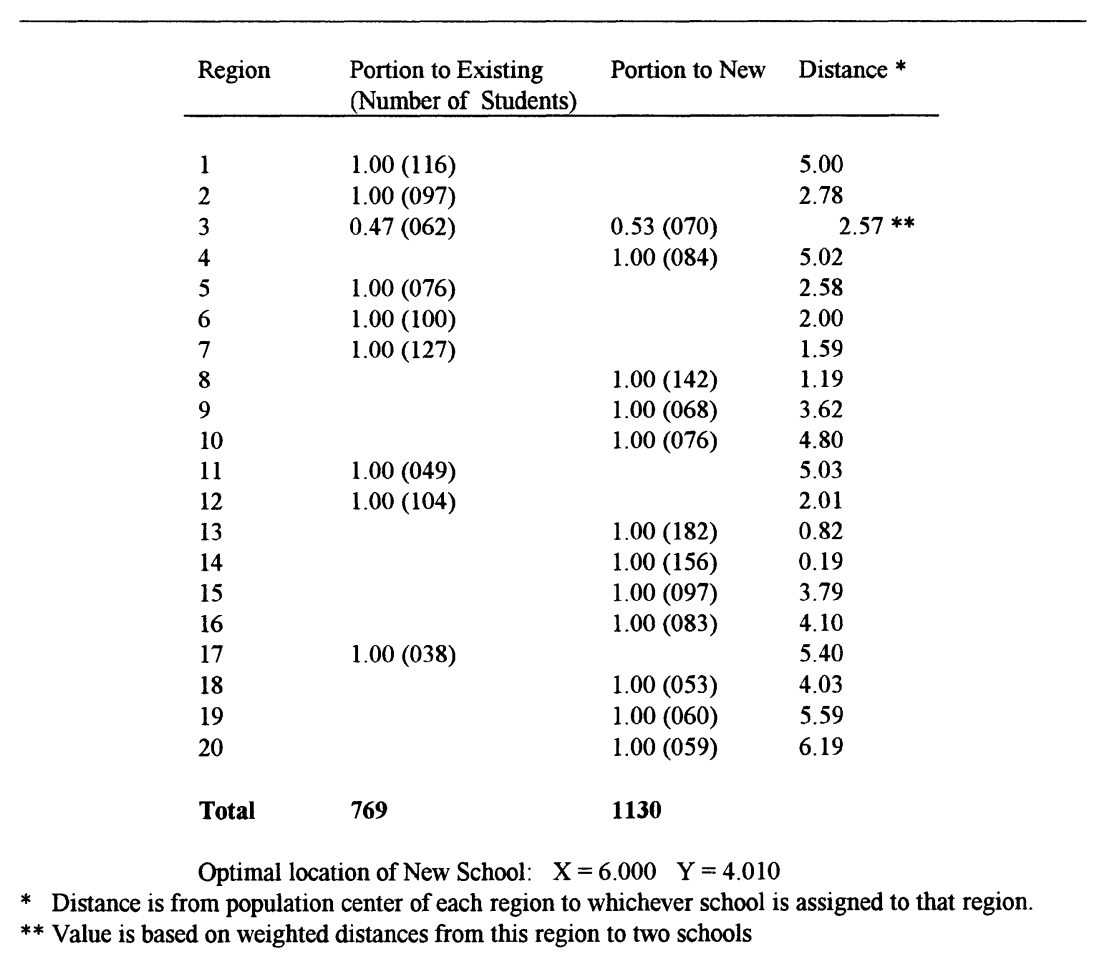


Geographic information and school facility planning

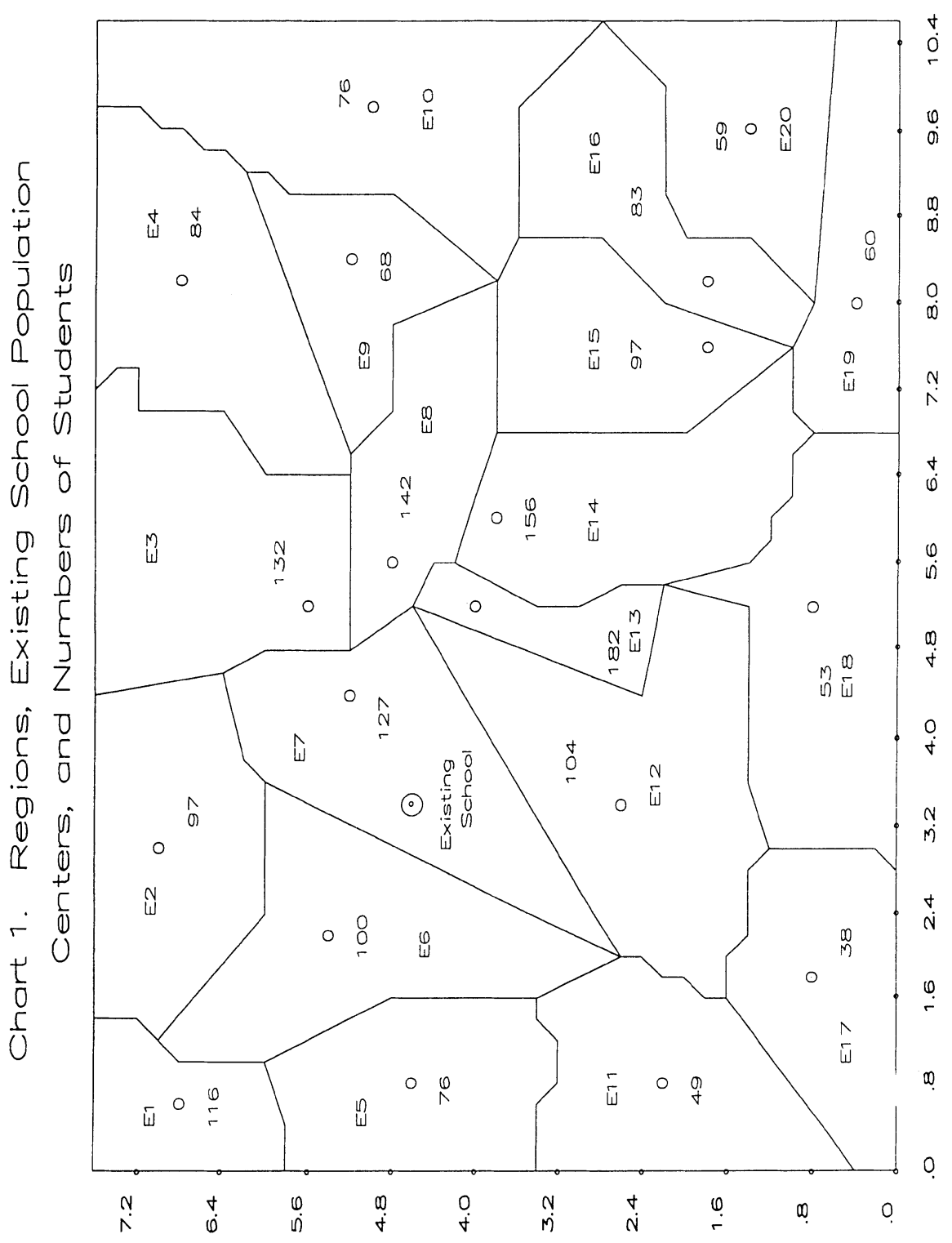




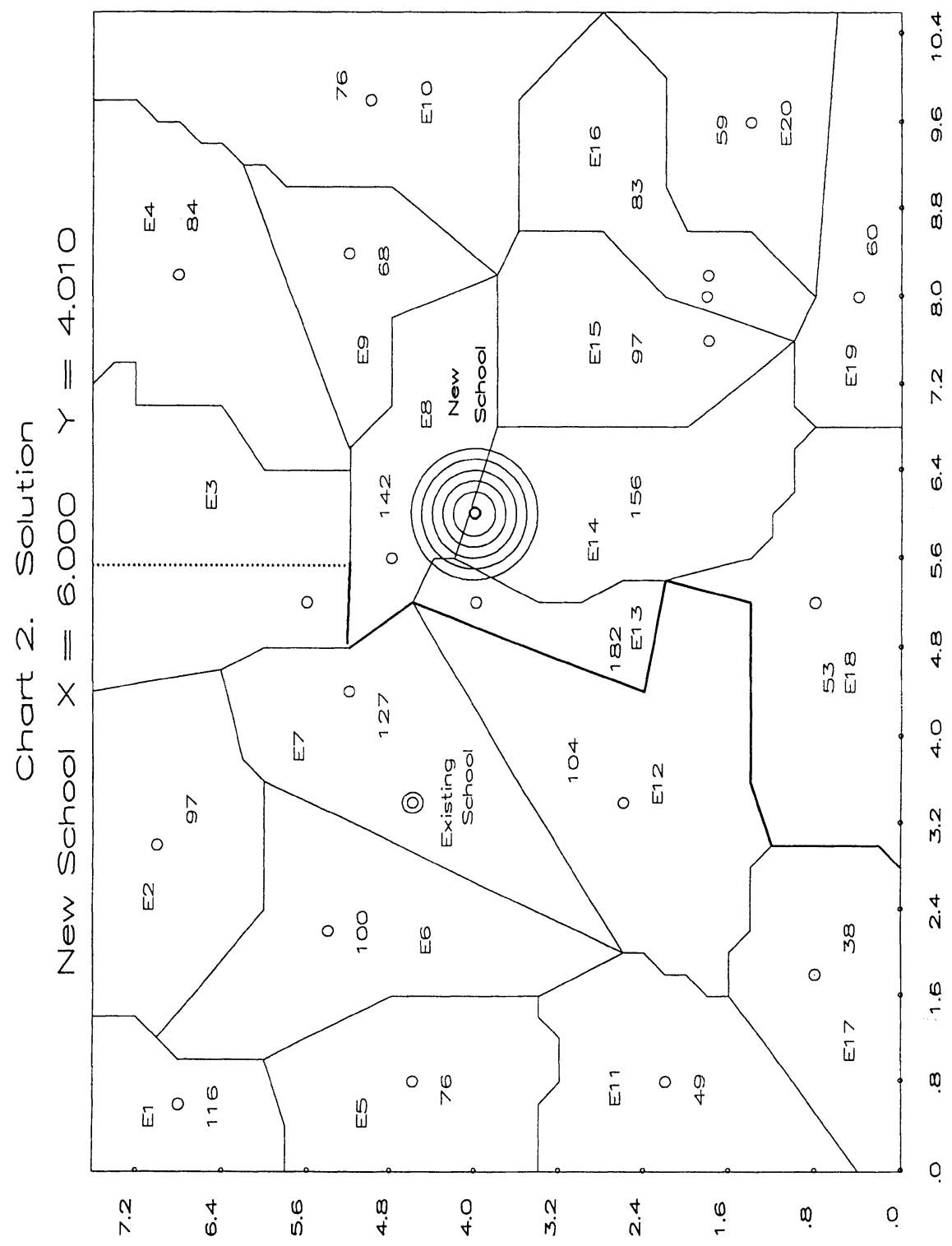




\section{REFERENCES}

1. B. Castaldi, Educational Facilities, (3rd ed.), Newton, MA, Allyn and Bacon, Inc., (1987).

2. Council of Educational Facility Planners, International, Guide for Planning Educational Facilities, Columbus, OH, Council for Educational Facility Planners, (1985).

3. C.W. McGuffey, McGuffey Model for School Site Location, Educational Facility Planner, 28 (1990) 20.

4. C.K. Tanner and C.T. Holmes, Microcomputer Applications in Educational Planning and Decision Making, New York, Teachers College Press, (1985).

5. A. Brooke, D. Kendrick, and A. Meeraus, GAMS, A General Algebraic Modeling System (Text and Software), So. San Francisco, CA, Scientific Press, (1988). 